\title{
EL CONTRATO BILATERAL
}

Siempre hubo de llamarme la atención el hecho que en el cód. civ. germano, fuera objeto de un tratamiento especial el contrato sinalagmático. El BGB en el título III de la sección tercera de su libro primero, se ocupa de los contratos. Dicho libro primero regula la parte general. Posteriormente, en el libro segundo, que trata del derecho de las relaciones obligatorias, existe una sección segunda cuyo título II se denomina "Del contrato sinalagmático", que comprende los parágrafos 320 al 327 inclusive. Este ensayo sirve para exponer ese tratamiento específico del contrato que la doctrina y la ley italiana llaman con prestaciones recíprocas.

Si bien el nuevo cód. civ. de Italia no contiene una parte especialmente dedicada al contrato con synallagma, sus autores, inspirándose en el BGB y en la doctrina de sus exégeta, tratan de él con respecto a la resolución, regulando la resolución por incumplimiento; por imposibilidad sobreviniente y por excesiva onerosidad. El legislador italiano ha distinguido la resolución del contrato, de la rescisión del contrato. En buena cuenta, significan a la postre lo mismo, en cuanto deshacen el contrato; pero la rescisión en el cód. civ. de Italia se produce: a) porque el contrato fue concluido en estado de peligro; $\mathrm{y} / \mathrm{o}$ b) por desproporción entre la prestación de una de las partes y la de la otra, siempre que esa desproporción obedeciera a un estado de necesidad aprovechado por la otra parte para obtener ventaja (véase arts. 1447 a 1452 del cód. civ. italiano).

Para dar una noción más clara del contrato bilateral, exponemos su regulación tanto en Alemania como en Italia.

Es el bilateral un contrato que se encuentra desdoblado en una pluralidad de obligaciones que deben cumplir cada una de las dos partes. Dícese de él que su esencia puede significarse en esta frase: "Yo estoy obligado para contigo, porque tú estás obligado para conmigo". Así es el contrato bilateral. Hay en él reciprocidad de prestaciones. Si yo doy un precio a cam- bio de una cosa, existirá contrato bilateral de compraventa. Si yo doy una merced por el uso de una cosa, habrá una locación; si yo recibo un salario por mi trabajo, habrá locación de servicios (contrato de trabajo); si se me paga por construir un edificio, existirá locación de obra.

El contrato de que estamos ocupándonos, no es sólo oneroso, sino con prestaciones recíprocas. El contrato oneroso no supone interdependencia entre las prestaciones. Por ejemplo, es un contrato oneroso el préstamo con intereses. No es sinalagmático o bilateral.

Dícese que es bilateral el contrato porque en realidad obliga bilateralmente. No obliga sólo unilateralmente. Son estrictamente unilaterales, por ejemplo, los contratos de mutuo y de donación. También son unilaterales, aunque no con la intensidad de los primeros, los contratos de mandato, de depósito gratuito y de como. dato.

El comodato no es un contrato bilateral no obstante que el comodante concede el uso de la cosa y el comodatorio se obliga a devolverla, porque esta última obligación no es la contra-partida de la otra; no existe reciprocidad en las obligaciones. Tampoco se puede decir que una obligación no se concibe sin la otra, ni media entre ambas obligaciones un nexo jurídico correlativo.

ENNECERUS (1) advierte que en su mayoría los contratos bilaterales son contratos de cambio, como la compra-venta y la permuta y también la locación. Las prestaciones se cambian. Tal prestación es la contra-partida de la otra u otras prestaciones. Agrega que si una prestación no llega a nacer, por cualquier causa, el contrato es nulo en su totalidad (2).

1 Trat. de D. Civ., t. II, D. de Obligaciones, vol. 1, (revisado por H. Lehmann), s. 32, № II, p. 162.

2 ENNECCRRUS L. con Lehmann, Trat. de D. Civ., t. II, D. de Obligaciones, vol. 1, s. 32, No III, p. 163. 
Para Karl LARENZ (3) la prestación simultánea es la nota de los contratos bilaterales. Cada contratante asume un deber de prestación, porque mediante ese deber recibe la contra-prestación del otro contratante. Agrega que el contrato bilateral es contrato de intercambio; las partes se cambian prestaciones, por lo que cada una de ellas recibe por la prestación que realiza la contra-prestación de la otra; los valores de ambas prestaciones son equivalentes no en un sentido objetivo, sino subjetivo. Las partes creen que existe equilibrio.

Base del contrato bilateral es el "do ut des", ya que la obligación de un contratante se asume bajo la condición de que el otro contratante se obligue a la contraprestación. De allí proviene también que la nulidad de la obligación de un contratante origina la nulidad de la obligación del otro contratante. Lo decisivo es que el contratante se obliga a una prestación porque debe recibir una contra-prestación.

En estos contratos cada parte sólo quiere realizar su prestación si al mismo tiempo recibe la contra-prestación. Y por eso, el contratante sólo puede exigir el pago de la contra-prestación que se le debe si ofrece la prestación que le respecta. De lo contrario, está expedita la deducción de la "exceptio non adimpleti contractus". Es claro que el demandado puede no oponer tal excepción, por lo que el juez sólo crdenaría el pago puro y simple de la excepción demandada.

En el cód. civ. italiano de 1942 ha desaparesido la mención de contrato bilateral y su diferencia con el contrato unilateral. Se trata ahora de contratos con prestaciones recíprocas y contratos con prestaciones de una sola parte.

Considera MESSINEO (4) que pensándolo bien no existe equivalencia entre contrato bilateral y contrato con prestaciones recíprocas, sino derivación o desarrollo de la más reciente respecto a la denominación antigua, que ha sido abolida.

En otro lugar, MESSINEO (5) expresa que el contrato $c c n$ prestaciones reciprocas se distingue porque cada una de las partes está obligáda a una prestación; existen prestación y contra-prestación, que son contra-puestas. Hay en esos contratos un nexo que se llama correspondencia o reciprocidad, por el que se observa una

3 D. de Obligaciones, t. I, $s .18$, p. 266.

4 Manual de D. Civ. y Comercial, t. IV, s. 135, No 4 bis, p. 477.

5 Manuel de D. Civ. y Comercial, t. IV, $s .135$, No 2, p. 473. Véase también de MESSINEO, Doctrina General del Contrato, t. I, p. 410. interdependencia o causalidad recíproca entre ambas prestaciones. Hay la singularidad de que el contratante no está obligado a la propia prestación, si no se le debe, por el otro contratante, una contra-prestación. Una "prestación es el presupuesto indeclinable de la otra". Cada contratante es al mismo tiempo deudor y acreedor.

Prestación y contra-prestación son heterogéneas, distintas: precio y cosa en la venta; cosa y cosa, en la permuta; precio y uso en la locación; precio y faccre o non facere, en otros contratos.

Otro carácter es que las prestaciones nacen al mismo tiempo, coexisten. $\mathrm{Y}$, sobre todo, deberán ser realizadas simultáneamente. MESSINEO dice "mano a mano" (6). Es por ello que uno de los contratantes puede negarse a cumplir si la otra parte no cumple; puede deducir una exceptio. Así, el art. 1400 del cód. de Ita. lia de 1942: "En los contratos con prestaciones recípro. cas, cada uno de los contratantes podrá rehusarse a cumplir su obligación si el otro no cumpliese u ofreciese cumplir simultáneamente la suya, salvo que las partes hubiesen establecido o que de la naturaleza del contrato resultasen términos diferentes para el cumplimiento". Y agrega: "Sin embargo, no podrá rehusarse la ejecución si, teniendo en cuenta las circunstancias, la negativa fuese contraria a la buena fe".

Nosotros tenemos esta exceptio que refleja el adagio "inadimplenti non est adimplendum", en el art. 1342, por la que se suspende por tiempo indeterminado el pago de la prestación. Sin embargo, ella no es, por lo general, oponible al tercero no contratante. La exceptio puede nacer cuando el otro contratante incumplido pretende que se le pague la prestación a que tiene derecho en el contrato bilateral.

Para J. W. HEDEMANN (7), en el contrato bilateral existe pluralidad de obligaciones distribuidas entre las dos partes y lo esencial es la paridad entre esas obligaciones. $X$ se obliga para con $Z$ porque, a su vez, $Z$ se obliga para con $X$, ya que ello deriva de la esencia del contrato. De ese entrecruzamiento de obligaciones surge lo sinalagmático.

Por ejemplo, en la compra-venta la cosa se da a cambio del precio; en la locación de obra la cosa se re-

6 Este sentido de la simultaneidad en el pago de las obligaciones tiene raíz popular, en cuanto a la venta de animales en que reza el dicho "Plata en mano, chivato en pampa". En igual sentido, cuando se exige la venta al contado.

7 D. de obligaciones, vol. III s. 4, No IV, p. 49. 
para en vista del pago del trabajo; en el arrendamiento de cosas el arrendatario está obligado a pagar el alquiler o merced a cambio del uso de la cosa locada; en la locación de servicios el obrero trabaja contra pago del salario. Eso no ocurre en los llamados contratos unilaterales, como la donación y el mutuo.

Del contrato sinalagmático derivan obligaciones recíprocas; obligaciones que se contraponen a! ser confrontadas. Esta nota de reciprocidad la tiene también el vulgo; todos tienen la conciencia de que se hace o se da algo a favor de otro, porque ese otro hace o da algo, en reciprocidad. Hay un intercambio de prestaciones, por lo que en el contrato bilateral existe una dependencia recíproca de dichas prestaciones.

Conviene saber que para HEDEMANN (8) el contrato bilateral es quizá el más importante de todo el derecho de obligaciones del cód. civ. alemán.

Es interesante conocer cómo regula el cód. alemán la teoría del riesgo en los contratos bilaterales. Nuestro cód. civ., siguiendo el ejemplo del cód. civ. de NAPOLEON, nada dice; y sólo teniendo en cuenta el art. 1172 (la sola obligación de dar una cosa inmueble determinada hace al acreedor propietario de ella] y el principio romano "res perit domino", se acepta que no obstante no haberse entregado la cosa inmueble si ésta se pierde por caso fortuito, la pérdida la experimenta el comprador, que es ya el propietario por sólo el efecto del contrato. En el derecho alemán, en forma general, rigen los siguientes preceptos:

s. 323.- "Si la prestación que incumbe a una de las partes por virtud de un contrato sinalagmático se hiciera imposible por consecuencia de una circunstancia de que no deba responder ninguno de los contratantes, perderá esta parte el derecho a la contra-prestación; en caso de imposibilidad parcial, se reducirá la contraprestación, según lo dispuesto en los ss. 472 y 473 " (9).

8 D. de obligaciones, vo. III, s. 11, No I, p. 102.

9 En el derecho escrito de Italia, la solución es distinta. Dentro de la sección segunda del capítulo XIV del libro IV, en la parte que se ocupa de los contratos, en el cód. civ. italiano figura el art. 1465, que dispone:

"Contrato con efectos traslativos o contitutivos. En los contratos que transfiere la propiedad de una cosa determinada o cnstituye o transfieren derechos reales, la pérdida de la cosa por causa no imputable al enajenante o libera al adquiriente de la obligación de ejecutar la contraprestación, aunque la cosa no le huebiese sido entregada".

"La misma disposición se aplicará en el caso de
"Si con arreglo al $s$. 281 exigiere la otra parte la entrega de la indemnización pagada por el objeto debido - la cesión de la acción por indemnización, quedará obligada a la contra-prestación. Sin embargo, si el valor de la indemnización o de la acción correspondiente fuese inferior a la de la prestación debida, sufrirá la contra-prestación una reducción igual a la diferencia, con arreglo a lo prescrito en los $s s .472$ y 473".

"Si la contra-prestación no debida con arreglo a estas disposiciones se hubiese ya realizado, podrá repetirse lo pagado conforme a lo dispuesto sobre la restitución de lo adquirido sin causa".

s. 324.- “Si la prestación que incumba a una de las partes por virtud de un contrato sinalagmático se hiciese imposible por consecuencia de una circunstancia de que deba responder la otra parte, conservará la primera su derecho a la prestación. Deberá, sin embargo, dejar que se deduzca lo que haya economizado por consecuencia de su liberación, lo que adquiera empleando de otro modo su actividad, o dejado maliciosamente de adquirir" (la mala traducción es patente).

“Lo mismo sucederá cuando, a consecuencia de una circunstancia no imputable a una de las partes, se haga imposible la prestación que incumbe a esta última, en el tiempo en que estuviere en mora de aceptar la otra parte".

s. 325.-_'Si la prestación que incumba a una parte por virtud de un contrato sinalagmático se hiciese imposible a consecuencia de una circunstancia de que aquélla es responsable, podrá la otra parte pedir daños y perjuicios por la inejecución, o rescindir el contrato. En caso de imposibilidad parcial, si la ejecución no tie-

que el efecto translativo o constitutivo haya sido diferido hasta el vencimiento de un término".

"Cuando fuese objeto de la transferencia una cosa determinada sólo en su género, el adquiriente no quedará liberado de la obligación de ejecutar la contraprestación, si el enajenante hubiere hecho la entrega o si la cosa hubiere sido individualizada".

"En todo caso el adquiriente quedará liberado de su obligación si la transferencia estuviese sometida a una condición suspensiva y la imposibilidad ha sobrevenido antes que se cumpla la condición".

En forma general, la resolución del contrato está autorizada en el art. 1341 de nuestro cód. civ., que dispone:

"Hay condición resolutoria en todo contrato bilateral, y ésta se realiza cuando alguna de las partes falta al cumplimiento de la obligación en la parte que le concierne".

El art. 1109 del cód. civ. declara: 
ne interés para la otra parte, podrá ésta pedir daños y perjuicios por la inejecución de toda la obligación, con arreglo al párrafo $2^{\circ}$ del s. 280 , o rescindir el contrato".

“En lugar de pedir daños y perjuicios o la rescisión, podrá la otra parte hacer valer los derechos fijados por el s. 323".

“Lo mismo sucederá en el caso previsto en el $s .283$, cuando la prestación no se ejecute hasta expirado el plazo o esté parcialmente ejecutada en esa fecha".

Hay en estos preceptos muchas cuestiones que constituyen novedades en nuestro derecho escrito, aun cuando las consecuencias que enuncian están conformes a la justicia más pura.

Así, no existe en nuestro cód. civ. fórmula que disponga que en el contrato bilateral si una de las partes no puede cumplir su obligación por causa que no la constituya en responsable, pierde su derecho a exigir la obligación que debe la otra parte, como lo hace el ap. I del s. 323 del BGB. Menos aún: que hay derecho a exigir la obligación si se ha entregado la indemnización recibida por la pérdida de la obligación o si se ha cedido el derecho a hacerla efectiva (ap. Il del $s$. 323); y el derecho que tiene quien ha cumplido con su obligación a pedir su restitución, si la otra parte ha quedado liberada de cumplir su obligación por caso fortuito o fuerza mayor (ap. III del $s$. 323) (9 bis).

A lo más y dentro de una atmósfera vaga e incierta, tenemos el art. 1327 que dispone: "El deudor que se libere de responsabilidad por la pérdida o destrucción de la cosa, debe ceder al acreedor cualesquiera derechos que le hubiesen quedado relativos a ella". La limi-

"La condición resolutoria expresa opera de pleno derecho".

En el cód. civ. de 1852, su art. 1286 decía:

"Se supone que hay condición resolutoria en todo contrato bilateral, y que ésta se realiza cuando uno de los contratantes falta al cumplimiento de la obligación en la parte que le concierne".

También la resolución se produce aunque no hubiera culpa en uno de los contratantes, dentro de nuestro cód. civ., en el art. 1404 instalado dentro del contrato de compra-venta. Reza este precepto:

"Cuando por falta de entrega se rescinde la venta, si ha habido culpa en el vendedor, debe éste al comprador los impuestos y gastos del contrato y los perjuicios".

"Si no la ha habido, le debe sólo los impuestos y gastos".

En realidad, el precepto reproduce el art. $1371 \mathrm{del}$ cód, civ. de 1852 .

L.o importante es que aún sin culpa se produce la tación a los supuestos de pérdida o destrucción de la cosa hace inferir que tratándose de obligaciones que no se refieran a cosas, nada tiene que ceder el deudor liberado.

En el párrafo I del s. 324 el contratante tiene derecho a la obligación de que es acreedor, si la obligación que él debía no puede pagarla a causa de un hecho del otro contratante. $Y$ en el párrafo II del mismo 324 , se dispone que en el contrato bilateral, el contratante que debía una obligación que resultó de imposible cumplimiento en el intervalo en que el otro contratante acreedor se encontraba en mora de recibir ("mora credendi"), tiene derecho a la obligación que le corresponde recibir del moroso.

Nosotros, sin tener dispositivo alguno, inducimos que el deudor se encuentra obligado a conservar la cosa hasta su entrega al acreedor. $Y$ bien se advierte que las obligaciones no sólo tienen por objeto cosas.

$\mathrm{Y}$ en el s. 325 se prevé la hipótesis de que el contratante que debe la obligación no pueda pagarla por hecho que lo constituya en responsable, lo cual concede al contratante que es acreedor de esa obligación el derecho de pedir la indemnización de daños y perjuicios o la rescisión del contrato. Esta solución es rara, ya que los daños y perjuicios procedería también pedirlos en caso de rescisión o resolución contractual.

Tal como está redactada la fórmula (aceptando que la traducción sea buena) resulta que la rescisión o resolución del contrato no daría derecho a reclamar indemnización de daños y perjuicios.

resolución de la venta, si no se ha entregado la cosa vendida. Sin embargo, esta solución no se da si lo vendido es cosa inmueble. Así, si el inmueble no se entrega porque en la zona en que está situado existe una inundación anormal e imprevisible, la venta no se resolverá.

Sea que lo vendido fueren muebles o inmuebles, si la falta de entrega se debe a culpa del vendedor, además de la resolución, dicho vendedor deberá pagar indemnización de daños y perjuicios.

Otro contrato bilateral en que están relacionadas las causales de resolución, es el de arrendamiento.

El art. 1529 del cód. civ. enumera las causas por las que el locador puede pedir la resolución (en juicio sumario de desahucio, según la exposición de motivos del cód. de proc. civ., en su art. 952). Y dicha rescisión se produce aún por obligaciones no estipuladas en el contrato, sino por el incumplimiento de obligaciones legales como las de no introducir capitales bastantes para la labranza; o abandonar el cultivo; o no hacerlo como un buen padre de familia; o no introducir muebles suficientes en la casa. 
También se ocupa el $\delta .325$ del caso de que la imposibilidad de cumplimiento de la obligación sólo fuere parcial, pero siempre que esa imposibilidad derive de circunstancia que haga responsable al contratante deudor de dicha obligación. Da derecho al contratante acreedor a rechazar ese pago parcial y pedir daños y perjuicios por el no cumplimiento total de la obligación debida.

Esta última solución nos recuerda la de la mora, en que nuestro art. 1257 declara: "Cuando por efecto de la morosidad del deudor, la obligación resultare sin utilidad para el acreedor, podrá éste rehusar su ejecución, y exigir el pago de daños y perjuicios". Empero, para el BGB la hipótesis no es de mora. La norma la contiene también el BGB en su $s$. 286: "El deudor deberá indemnizar al acreedor del daño causado por su morosidad".

Y agrega: "Si a consecuencia de ésta no fuese ya útil la prestación para el acreedor, podrá éste rehusarla y reclamar daños y perjuicios por inejecución de la obligación. Son aplicables a esta materia por analogía, las disposiciones de los ss. 346 a 356 sobre rescisión convencional".

Es claro que una cosa es mora y otra distinta la imposibilidad parcial de la obligación, en la que no hay retardo sino disminución de la prestación.

Véase así la conveniencia de que nuestro código regule el contrato bilateral en forma autónoma, con sus peculiares efectos de la excepción de contrato no cumplido, la condena al cumplimiento simultáneo de ambas obligaciones y la resolución del contrato.

Es también necesario expresar que el principio de la culpa del deudor es observable en los contratos bilaterales.

$Y$ las consecuencias que se producen en el derecho alemán, son las que siguen:

1.- Si ninguno de los contratantes es responsable el deudor se libera. V. g., X vende harina de pescado a $Z$, pero viene una orden del gobierno prohibiendo la pesca, es incuestionable que el vendedor $X$ no tiene responsabilidad; empero, perderá también su pretensión para reclamarle a $Z$ el precio, o sea la contra-prestación de éste. Y si $Z$ había entregado el precio, tiene el derecho de exigir su devolución a $X$, ya que éste se habría enriquecido sin causa.

Si el contratante acreedor de la prestación que se ha hecho imposible sin responsabilidad de ninguno de los contratantes, reclama la entrega de la indemnización pagada por el objeto debido, o sea el valor sustitutivo del objeto (por ejemplo, un tercero extraño mató el animal vendido y que debía entregarse), entonces - conforme al ap. II del $s$. 323- dicho contratante acreedor debe también cumplir con la obligación que como deudor le respecta. HEDEMANN (10), acerca de esta solución legislativa, pone este ejemplo: el comprador debe pagar como precio, por la venta del animal, sólo 3,000 , pero su valor $y$, por tanto, la indemnización se eleva a 5,000. El comprador reclama esta indemnización que le permite ganar 2,000 , ya que él sólo debe como precio 3,000 .

Un caso raro es el legislado en el $s .324$ del BGB: el contratante acreedor es responsable de la imposibilidad de la obligación. También en el derecho alemán, el deudor queda liberado del cumplimiento de la obligación; el s. 275 reza, "El deudor queda liberado de su obligación cuando la prestación se haga imposible por consecuencia de una circunstancia sobrevenida después del nacimiento de la relación obligatoria y de la que él no es responsable". Y agrega: "Se equiparará el caso de imposibilidad mencionado aquel en que el deudor se incapacite ulteriormente para hacer la prestación". Con demasiada brevedad, nuestro art. 1318 declara: "La obligación se extingue cuando la prestación llega a ser imposible sin culpa del deudor". Empero, lo importante no es en el contrato bilateral, sólo la liberación del contratante deudor, sino que dicho contratante conserva su pretensión a exigir la obligación que se le debe por el otro contratante. En este caso, sin embargo, deberán ser evaluados los eventuales ahorros que este contra. tante que conserva su pretensión a exigir la obligación que, a su vez, se le debe, hubiera hecho al quedar liberado. HEDEMANN (11) pone este ejemplo: El vendedor se libera de entregar el caballo vendido por muerte ocasionada por culpa del comprador. Ello no obstante, tiene derecho a reclamar el precio, pero deberán deducirse los gastos que ha dejado de hacer para mantener al caballo. En otros casos, deben ser evaluadas las cantidades que ha podido percibir el contratante deudor, por haber recobrado su libertad de trabajo, la cual está en condiciones de utilizar para otros fines.

Conviene, antes de seguir adelante, ocuparnos de un problema grave, con que se enfrenta quien pretende estudiar derecho civil alemán:

10 D. de Obligaciones, vol. III, $s .20, \mathrm{~N}^{\circ}$ III, p. 173 11 D. de Obligaciones, vol. III, $s .20$, No III, p. 173. 
Otra traducción del s. 275 del BGB que no contiene el enormísimo error de disponer que habrá imposibilidad de la prestación si el deudor se incapacita, es la que sigue:

"El deudor queda libre de la obligación a la prestación siempre que ésta se haga imposible a consecuencia de alguna circunstancia de la que no ha de responder ocurrida después del nacimiento de la relación obligatoria".

"A una imposibilidad sobrevenida después del nacimiento de la relación obligatoria se equipara la imposibilidad del deudor para la prestación sobrevenida con posterioridad".

Se trata de una reciente traducción del cód. civ. alemán, que ha hecho Carlos MELON INFANTE (12). No se crea que ésta es una traducción aprovechable en todos los casos, ya que también contiene frases ininteligibles. En realidad, son las malas traducciones de los libros de derecho germano, en general, las que hacen inaprehensible y extraña su doctrina.

Debo expresar, asimismo, que los preceptos del BGB que hemos reproducido corresponden en su mayoría a una vieja traducción del Código Civil del Imperio Alemán, hecha sin ningún cuidado (13).

LARENZ (14) claramente dice que si en el contrato bilateral uno de los contratantes se libera de su obligación (deber de prestación) en observancia del s. 275 , carece de derecho para reclamar del otro contratante su contra-prestación, a no ser que de la imposibilidad de cumplir con su obligación deba responder el otro contratante ( $s .323$, ap. I del cód. civ. alemán). Agrega que a este resultado se arriba por aplicación de los principios esenciales del contrato bilateral, ya que toda prestación se hace en virtud de la contra-prestación de la otra parte. Es evidente que si no se puede reclamar la obligación que se ha hecho imposible, no se estara tampoco obligado a cumplir con la prestación que se debe. Resulta así que aquel contratante que no puede cumplir con su obligación porque ésta es imposible pierde su pretensión a la contra-prestación del otro contratante. De donde se sigue que el contratante que ha expe-

12 Es el Apéndice del Trat. de D. Civ. escrito por ENNECCERUS, KIPP y WOLFF, y ha sido editado en el año de 19.

13 Se encuentra en el Apéndice VI del Complemento de las Instituciones Jurídicas y Políticas de los Pueblos Modernos, por Vicente Romero Girón y Alejo García Moreno, Centro Editorial de Góngora, Madrid, 1897.

14 D. de Obligaciones, t. I, s. 20, p. 306 y s. rimentado la imposibilidad de la prestación que debía cumplir soporta el riesgo de perder la contra-prestación que se le debe. $\mathrm{Y}$, a su turno, el contratante que debía recibir la prestación no sólo se libera de cumplir con su contra-prestación, sino que soporta el riesgo de la prestación que se le debía y que se ha hecho imposible.

Esta es una solución simple y justa de la teoría del riesgo, que debe ser recogida por nuestro cód. civ. que se quiere reformar. Hay excepciones en el BGB a la regla general del $s$. 323, en las que el contratante deudor de la prestación, siempre para él subsiste su obligación de realizar la prestación que debe, no obstante que ha llegado a ser imposible la prestación del otro contratante. Veamos estos preceptos:

s. 447.- "Cuando, a petición del comprador, expida el vendedor la cosa vendida en lugar distinto al de la ejecución, los riesgos pasarán al comprador en cuanto aquél haya entregado la cosa al consignatario, al porteador o a cualquier otra persona o establecimiento encargado de la ejecución".

"Si el comprador hubiese dado instrucciones especiales sobre el modo de expedición, el vendedor que sin necesidad se separe de estas instrucciones, será responsable para con el comprador del perjuicio que de su hecho resulte".

Una reciente traducción del $s .447$ trae este texto:

"Si el vendedor, a requerimiento del comprador, envía la cosa vendida a un lugar distinto del lugar de cumplimiento, el riesgo pasa al comprador tan pronto como el vendedor haya entregado la cosa al expedidor, al trans portista o a la persona o establecimiento determinado de otra forma para la realización del envío".

"Si el comprador ha facilitado alguna especial indicación acerca de la forma del envío y el vendedor se separa de la indicación sin imperioso motivo, dicho vendedor es responsable para el comprador del daño causado por esto".

Tampoco es buena esta traducción, aun cuando la idea del riesgo aparece nítidamente configurada.

En el contrato de locación de servicios (contrato de trabajo), que es bilateral, subsiste la prestación a cargo de una de las partes en el supuesto contemplado en el $s$. 616, no obstante que la contra-prestación de la otra parte se ha hecho imposible. Dice la norma:

“El obligado a la prestación de los servicios no se ve privado de la pretensión a la remuneración por la 
circunstancia de que se encuentre entorpecido sin su culpa para la prestación de los servicios, por un motivo referente a su persona, mediante un tiempo no considerable proporcionalmente. Debe, sin embargo, dejarse imputar la suma que le corresponda, por el tiempo del entorpecimiento, por un seguro de enfermedad o accidente existente en base a una obligación legal".

Lo mismo ocurre en el contrato de locación de obra:

s. 644.- “El artífice soporta el riesgo hasta la admisión de la obra. Si el comitente incurre en mora en la aceptación, el riesgo pasa a él. El artífice no es responsable de la pérdida fortuita o de un menoscabo fortuito del material suministrado por el comitente".

"Si el artífice, a petición del comitente, envía la obra a un lugar distinto del lugar de cumplimiento, se aplican oportunamente las disposiciones existentes en el parágrafo 447 para la compraventa".

Nuestro código civil carece de una disposición como la anterior. A lo más su art. 1533 declara que si el empresario pone materiales e industria habrá unà venta. No se sabe si es venta de cosa inmueble o mueble. Si lo primero, la pérdida la experimenta el dueño de la tierra donde se hace la construcción. Pero si es venta de cosa mueble, la pérdida la sufre el constructor por no haberla entregado todavía (15).

Debe tenerse en cuenta también el art. 1558 del vigente cód. civ. peruano, que contempla un caso de mora del acreedor. Producida su mora habrá de soportar el riesgo. Se trata del caso en que el empresario pone a disposición del propietario la obra y éste "sin justa causa" no la recibe.

En el párrafo II del $s$. 324 del BGB se examina la hipótesis de que el contratante acreedor hubiere incurrido en mora "accipiendi", estableciéndose que si ambos contratantes no incurrieron en culpa y la prestación del no moroso resultó imposible, ello no impide que el contratante deudor pueda exigir el cumplimiento de la obligación que se le debe por quien estuvo en mora de recibir.

El caso que se da con más frecuencia en el contrato bilateral es el previsto en el $s .325$ del cód. civ. germano. V. g., la cosa mueble que se ha vendido y no entregado, se vende a otro a quien se entrega y que, por tanto, no puede obtenerse de este segundo adquiriente la devolución. Corresponde al contratante acreedor de la

15 Teoría del riesgo perfecto de la transferencia de la propiedad en la renta inmobiliaria. cosa, o sea el comprador, elegir entre la indemnización de daños y perjuicios o la resolución del contrato de compra-venta.

HEDEMANN (16) expresa que el contratante acreedor demandará la resolución, si se percata después que el contrato le era desfavorable; y que de lo contrario, elegirá la indemnización de daños y perjuicios. Ejemplo: $X$ y $Z$ celebran un contrato de permuta. $X$ da un caballo a cambio de un buey de casta que dará $Z$. Empero, $Z$ enajena a tercero a título oneroso, el buey, por lo que la obligación que le respecta a $Z$ tórnase imposible. Si X comprueba que su obligación de dar un caballo era de valor superior, no reclamará indemnización de daños por la no entrega del buey, o sea que existirá resolución. Si en cambio, $X$ comprueba que la obligación de su contratante de darle el buey es de mayor valor, se aferrará al contrato y exigirá el pago de una indemnización en dinero por el mayor valor del buey.

De acuerdo con el apartado II del $s$. 325, el contratante acreedor puede si así lo desea, encusdrar el caso dentro del precepto contenido en el is. 323, es decir, considerarlo como si la imposibilidad de cumplir con la obligación no fuese imputable a ninguno de los dos contratantes del contrato sinalagmático; y así podía obtener la indemnización de daños y perjuicios que pagaria el tercero y que está prevista en el $s$. 281, el cual dispone: "Si a consecuencia de la circunstancia que hiciere imposible la prestación, obtuviere el deudor una indemnización por el objeto debido, o un derecho de indemnización, podrá el acreedor exigir la entrega de la indemnización recibida, o la cesión del derecho a recibirla". Otro párrafo de este mismo $s .281$ dice: "Si el acreedor tuviese derecho a los daños y perjuicios por inejecución, disminuirá tal derecho cuando haga uso del (derecho) indicado en el párrafo precedente, del valor de la indemnización obtenida o de otro derecho análogo".

Volviendo a examinar el supuesto de que en el contrato bilateral el contratante acreedor puede, en virtud del s. 325, pedir daños y perjuicios por inejecución, o resolver el contrato, si la obligación se hizo imposible a causa de una circunstancia de la que era responsable el contratante deudor, debemos consignar que la resolución siempre supone el pago de los daños y perjuicios, conforme a lo dispuesto en el s. 347 del BGB. Así, si quien debe restituir el objeto lo ha deteriorado por su culpa, o por esta misma causa hubiere perecido, o

16 D. de Obligaciones, vol. III $s .20$, No III, p. 174. 
por cualquiera otra razón no pudiera ser entregado; o si hay frutos que devolver de la cosa y no los hay por su culpa, deberá indemnización en dinero (17).

Otra cuestión que debe ser examinada es la que se refiere al segundo párrafo del ya reproducido $s$. 275, o sea que el deudor se libera de la obligación si la prestación resulta imposible a causa de la imposibilidad y no de la incapacidad sobreviniente de dicho deudor. A este respecto, HEDEMANN (18) titula como "inexigibilidad psíquica" esta hipótesis legal, expresando que el pago de la obligación impondría una excesiva e injustificada carga anímica o afectiva, y también significaría un riesgo personal; y pone como ejemplo el del actor al que no se le puede exigir que salga a escena si a la misma hora se encuentra moribunda su mujer. En todo caso, se trataría de la llamada "imposibilidad subjetiva", por distinguirla de la "imposibilidad objetiva". De las dos incapacidades habla el $s$. 275. .Sin embargo, la imposibilidad subjetiva es tratada en forma distinta en el s. 279, que dice: "Si el objeto debido sólo estuviese determinado en su especie, mientras sea posible la prestación de un objeto de la misma clase, responHerá el deudor de su incapacidad personal de efectuar la prestación, aunque no haya incurrido en culpa".

La declaración del apartado II del s. 275 podría ser tomada en el sentido de que si el deudor deviene incapaz (por ejemplo, por enajenación mental), debe considerarse que la obligación se ha tornado de imposible cumplimiento, lo cual no es verdad. En tal caso, deberá cumplir la obligación del incapaz su representante legal (padre, tutor, o curador).

Es también privativo del contrato sinalagmático el régimen de la "exceptio non impleti contractus", que el cód. alemán la trata con precisión y no en la forma empírica en que se encuentra regulada en nuestro código, cuyos arts. 1342 y 1343 son insuficientes, dando su aplicación jurisprudencial lugar a equívocos.

\section{Existen en el BGB las siguientes disposiciones:}

s. 320.- "El obligado por virtud de un contrato sinalagmático podrá negarse a hacer la prestación que le incumba hasta que se haga la contra-prestación, a no ser que se haya obligado a hacerla inmediatamente. Si la prestación hubiere de hacerse a varios derecho-habientes podrá rehusarse la parte correspondiente a cada uno hasta que se realice toda la contra-prestación.

17 Véase J. W. HEDEMANN, D. de Obligaciones, vol. III, s. 17, III p. 146.

18 D. de Obligaciones, vol. III $s .20$, No I, p. 169.
No es aplicable a esta materia lo dispuesto en el párrafo $3^{\circ}$ del s. 273 ".

"Si la prestación ha sido parcialmente ejecutada por una de las partes, no podrá rehusarse la contra-prestación cuando la negativa sea contraria a la buena fe, lo cual se aprecia teniendo en cuenta las circunstancias, y en particular la insignificancia de la parte restante".

s. 321.-_"Cuando cualquiera esté obligado a prestar inmediatamente en virtud de un contrato sinalagmático, y después de la conclusión del contrato sobrevenga en la fortuna y posición de la otra parte un cambio tal que comprometería el derecho a la contra-prestación, podrá negarse a hacer la prestación que le incumbe hasta que se haga la contra-prestación, o se le den suficientes se. guridades".

s. 322.--"Si en la ejecución de un contrato sinalagmático una de las partes reclamase judicialmente la prestación que se le debe, se reducirá el derecho de la parte demandada, no a negar la prestación hasta que se haga la contra-prestación, sino a que se ejecuten si. multáneamente".

"Si la parte demandada debiera ejecutar la primera (prestación) y el otro contratante incurriese en morá respecto de la aceptación, podrá aquélla pedir que sea éste condenado a aceptarla después de haber recibido la contra-prestación".

"En caso de ejecución forzosa, será aplicable lo dispuesto en el párrafo $2^{\circ} \mathrm{del} s .271^{\prime \prime}$.

El párrafo $2^{\circ}$ del $s .271$ dice:

"Si se hubiese fijado una época, habrá que admitir, en caso de duda, que el acreedor no podrá exigir 'a prestación antes de la misma, pero el deudor podrá efectuarla".

También el BGB contiene una aplicación específica de la exceptio dentro del contrato de mutuo. Es el $s$. 610 , que reza:

"El que prometa hacer un préstamo, en caso de duda, podrá revocar su promesa cuando el estado de fortuna de la otra parte sufra una alteración esencial que ponga en peligro el derecho a la restitución".

No sólo conviene sustituir, en el art. 1341 del cód. civ., la frase "condición resolutoria" por otra, ya que da origen a muchas confusiones, así como suprimir el art. 1109 del cód. civ., en cuanto que al declarar éste que la condición resolutoria expresa opera de pleno derecho, ello corresponde a la resolución del contrato bi- 
lateral, pero no a la teoría de las auténticas condiciones suspensivas y resolutorias, en cuyo título ha sido instalado el precepto 1109 , sino que la resolución o rescisión de todo contrato sinalagmático no debe necesariamente producirse con la citación con la demanda de resolución, sino que debe darse al cocontratante un término para que pueda cumplir la prestación que le respecta, como lo dispone el $s .326$ del BGB, que declara:

"Si en un contrato bilateral una parte está en mora en cuanto a la prestación que le incumbe, la otra parte puede señalarle un plazo prudencial para la efectuación de la prestación con la declaración de que rehusará la aceptación de la prestación después del transcurso del plazo. Después del transcurso del plazo está autorizada a exigir indemnización de daños a causa de no cumplimiento o a desistir del contrato, si la prestación no está realizada a tiempo; la pretensión al cumplimiento está excluida. Si la prestación, hasta el transcurso del plazo, no es efectuada en parte, se aplica oportunamente la disposición del $s .325$, párrafo 19 , inciso $2^{\circ} "$ ".

"Si el cumplimiento del contrato no tiene ningún interés para la otra parte a consecuencia de la mora, le corresponden los derechos indicados en el párrafo $1^{0} \sin$ que sea necesaria la determinación de un plazo (19)

19 El parágrafo 325 previene:

"Si la prestación que incumbe a una parte, derivada de un contrato bilateral, se hace imposible a consecuencia de una circunstancia de la que ha de responder, la otra parte puede exigir indemnización de daños a causa de no cumplimiento o desistir del contrato. En caso de imposibilidad parcial, si el cumplimiento parcial del contrato no tiene para ella interés alguno, está autorizada a exigir indemnización de daños a causa de no cumplimiento de toda la obligación, de conformidad con el parágrafo 280 , párrafo 2 ․, o a desistir de todo contrato. En lugar de la pretensión de indemnización de daños y del derecho de resolución puede también hacer valer los derechos señalados para el caso del parágrafo 323 ".

"Lo mismo vale en el caso del parágrafo 283 si la prestación no es efectuada hasta el transcurso del plazo o si en este tiempo no está realizada en parte".

Hemos reproducido todo el parágrafo; empero, sólo debe tenerse en cuenta lo dispuesto en él para el caso de imposibilidad parcial.

Se hace referencia en la disposición a otros parágrafos que se transcriben:

s. 323.- "Si la prestación que incumbe a una parte, derivada de un contrato bilateral, se hace imposible a consecuencia de una circunstancia de la que no ha de responder ni ella ni la otra parte, pierde la pretensión a la contraprestación; siendo parcial la
No siempre la resolución o rescisión del contrato bilateral da en el derecho alemán, como en todo derecho, una pretensión de indemnización o resarcimiento en quien pide resolver el contrato porque el otro contratante no cumple con la prestación que le respecta. V. g., no existiría derecho a reclamar la indemnización de daños y perjuicios por la resolución, si la prestación de la otra parte que justifica la resolución, se hizo imposible sin culpa del contratante que la debe.

Con respecto al contrato bilateral el cód. alemán contiene también el $s$. 361:

"Si en un contrato bilateral está estipulado que la prestación de una parte deba ser realizada exactamente en un tiempo prefijado o dentro de un plazo preestablecido, en la duda ha de entenderse que la otra parte está autorizada a la resolución si la prestación no se realiza en el tiempo determinado o dentro del plazo fijado".

No existe en nuestro cód. civ. una regla como ésta, que establece la mora automática.

En cuanto al plazo si no le ha sido fijado a la prestación, nuestro cód. en su art. 1252 autoriza que pueda

imposibilidad se aminora la contraprestación de conformidad con los parágrafos 472 y 473".

"Si la otra parte exige, según el parágrafo 281 , entrega de la indemnización obtenida por el objeto debido o cesión de la pretensión de indemnización, queda obligada a la contraprestación; ésta se aminora. sin embargo, de conformidad con los parágrafos 472 y 473, en la medida que el valor de la indemnización o de la pretensión de indemnización quede por debajo del valor de la prestación debida".

"Siempre que se haya efectuado la contraprestación no debida según estas disposiciones, lo pagado puede ser repetido según las disposiciones sobre la entrega de un enriquecimiento injusto".

s. 280.- "Siempre que la prestación se haga imposible a consecuencia de una circunstancia de que ha de responder el deudor, éste ha de indemnizar al acreedor el dano causado por el no cumplimiento".

"En el caso de imposibilidad parcial, el acreedor, rechazando la parte de prestación aún posible, puede exigir indemnización de daños a causa del no cumplimiento de toda obligación, si el cumplimiento parcial no tiene para él ningún interés. Se aplican oportunamente las disposiciones existentes en los parágrafos 346 a 356 para el derecho de resolución convencional".

s. 283.- "Si el deudor está condenado en firme, el acredor puede señalarle un plazo oportuno para la efectuación de la prestación con la declaración de que después del transcurso del plazo rehusará la aceptación de la prestación. Después del transcurso del plazo, el acreedor puede exigir indemnización de 
exigir el pago de la prestación inmediatamente después de contraída.

Para el cód. civ. italiano de 1942, su art. 1453 dispone:

"En los contratos con prestaciones recíprocas, cuando uno de los contratantes no cumpliese su obligación, el otro podrá, a su elección, pedir el cumplimiento o la resolución del contrato, sin perjuicio en todo caso del resarcimiento del daño".

“La resolución podrá ser demandada también aunque el juicio hubiese sido promovido para obtener el cumplimiento; pero no podrá pedirse ya el cumplimiento cuando se hubiera demandado la resolución".

“Desde la fecha de la demanda de resolución, el incumplidor ya no podrá cumplir su obligación".

Esta es la condición resolutoria tácita del art. 1341 del cód. civ. peruano, de la que MESSINEO dice que no se puede concebir que la resolución de un contrato por incumplimiento tenga por origen la realización de la condición resolutoria, ya que la resolución se verifica sólo por iniciativa de la otra parte y no ope legis, como ocu-

daños a causa de no cumplimiento, siempre y cuando que no sea efectuada la prestación en tiempo oportuno; la prestación al cumplimiento está excluida. La La obligación de indemnización de daños no tiene lugar si la prestación se hace imposible a causa de una circunstancia de la que no ha de responder el deudor".

"Si hasta el transcurso del plazo la prestación es sólo en parte efectuada, corresponde al acreedor también el derecho señalado en el parágrafo 280 , párrafo 2 ".".

s. 472.- "En la reducción el precio de compra ha de reducirse en la proporción en que habría estado, al tiempo de la venta, el valor de la cosa en estado de ausencia de vicios con el valor real".

"Si en el caso de venta de varias cosas por un precio total la reducción sólo tiene lugar a causa de algunas cosas, en la reducción del precio ha de tomarse como base el valor total de todas las cosas".

$\mathrm{El}$ anterior precepto y el que sigue se encuentran en el BGB dentro del capítulo de la compra-venta que se ocupa del saneamiento a causa del vicio de la cosa.

s. 473.-"Si junto al precio de compra fijado en dinero se han estipulado -otras- prestaciones que no tienen por objeto cosas fungibles, estas prestaciones en los casos de los parágrafos 471 y 472, han de estimarse en dinero según el valor al tiempo de la venta. La reducción de la contraprestación del comprador se realiza en el precio fijado en dinero; si éste es menor que la suma a reducir, el vendedor ha de compensar al comprador la suma excedente". rriría en la condición resolutoria. Hace notar también que la resolución del contrato depende de eventos típicos como son el incumplimiento de la prestación por uno de los contratantes y no de cualquier evento futuro e incierto como ocurre en la condición resolutoria. Este es un poder de resolución que emana de la ley (20).

No desde la fecha de la citación con la demanda de resolución, sino desde la fecha de la misma demanda, no podrá el contratante que debe cumplir con su prestación cumplirla, (ap. 4 del art. 1453).

En nuestro derecho, la resolución del contrato porque una de las partes no cumple con la obligación que ha asumido, procede aun cuando dicha obligación se hiciere imposible sin culpa del contratante, salvo el caso excepcional de la venta inmobiliaria (consumada solo consensus) en que la cosa, v. g., no se hubiere entregado y se hubiere perdido por en casus posesión del vendedor, o algún otro como el de mora en recibir de parte del acreedor. No es necesario que el contratante incumplidor incurra en dolo o negligencia. No lo cree así MESSINEO (21) en vista de la referencia que contiene el ap. I del art. 1453 al resarcimiento del daño, ya que la obligación de indemnizar se da cuando el incumplimiento de la prestación se debe a culpa del contratante. $Y$ termina diciendo: "Por consiguiente, no hay lugar a resolución sin culpa (o dolo) del incumpliente". $Y$ en realidad, atendido el carácter del contrato sinalagmático, la resolución operará siempre si uno de los contratantes no cumple con su obligación por cualquier causa, aunque no pueda atribuirsele responsabilidad alguna, Es por eso que en el derecho alemán puede existir resolución del contrato sin que la parte que lo ha incumplido se encuentre obligada a satisfacer daños y perjuicios.

MESSINEO (22) insiste en su Manual, en esta misma opinión. Textualmente expresa: "No hay lugar a resolución si el incumplimiento es debido a causa no imputable al deudor; la prueba de lo cual incumbe al deudor".

20 Doctrina General del Contrato, t. II, Ediciones Europa-América, B. Aires, 1952, cap. XV, No 3, p. 337.

21 Doctrina General del Contrato, t. II, cap. XV, № 4, p. 343.

22 Manual de Derecho Civil y Comercial, t. IV, Ediciones Jurídicas Europa-América, Buenos Aires, 1955, № 10, p. 524 . En la n. 9 de la p. 524 cita a AULETTA, La risoluzione per inadempimento, Milano, 1942; y MOS$\mathrm{CO}$, La risoluzione del contratto per inadempimento, Napoli, 1950. 
El contrato con prestaciones recíprocas, en el derecho italiano, es susceptible de ser rescindido y, por tanto, privado de sus efectos, sea porque fue concluido en estado de peligro, sea porque se hubiere producido lesión para una de las partes determinada por el estado de necesidad experimentado por dicha parte, la que fue inducida a celebrar el contrato (23). Esta acción de rescisión prescribe en un año, a no ser que se hubiere cometido delito: art. 1449, s. $1^{\text {o }}$ del cód. civ. italiano, que dispone:

"La acción de rescisión (que es en el cód. italiano, distinta de la acción de resolución del contrato) se prescribe al año desde la conclusión del contrato; pero si el hecho constituyera delito, se aplicará el último parágrafo del art. 2947".

"La rescindibilidad del contrato no podrá oponerse por vía de excepción cuando la acción hubiese prescrito".

Consiste el estado de peligro en que el motivo determinante para contratar (aunque el contrato fuere aleatorio), ha sido la necesidad que tenía una de las partes. conocida de la otra parte, de salvarse a sí misma, o de salvar a otro del peligro actual de un daño grave a la persona (contrato en estado de necesidad); y, además, que la obligación fue contraída en condiciones contrarias a la equidad (inicuas). Declara el art. 1447, $s$. 19:

"El contrato mediante el que una de las partes hubiese asumido obligaciones en condiciones inícuas, por la necesidad conocida por la otra parte de salvarse a sí misma o salvar a otros del peligro actual de un daño grave a la persona, podrá rescindirse a instancia de la parte que se haya obligado".

Y también véase el art. 2045 del mismo cód., que dispone:

"Cuando quien ha cometido el hecho dañoso ha sido constreñido a ello por la necesidad de salvar a sí mismo o a otro del peligro actual de un daño grave a la persona, y el peligro no ha sido causado voluntariamente por él ni era evitable de otra manera, al perjudicado se le debe una indemnización cuya medida se deja a la equitativa apreciación del juez".

Existe una desproporción notoria entre la prestación y la contraprestación.

Otra causa de rescisión del contrato en el derecho italiano, es la lesión patrimonial que consiste en la lesión

23 MESSINEO F., Manual de D. Civ. y Com., t. IV, B. Aires, $1955, \mathrm{~N}^{\circ} 5$ del s. 137, p. 519 y s. o desequilibrio que existe entre la obligación que ha contraído el lesionado y la obligación que debe recibir. Esa desproporción se produce por el estado de necesidad en que se encontraba el lesionado y que fue el motivo determinante para que la otra parte se aprovechara y obtuviera ventajas abusivas.

A este respecto, el art. 1448 del cód. de Italia dice:

"Si hubiese desproporción entre la prestación de una de las partes y la de la otra y la desproporción dependiese del estado de necesidad de una de ellas, de la que se ha aprovechado la otra para obtener ventaja, la parte damnificada podrá demandar la rescisión del contrato".

"La acción no será admisible si la lesión no excediese la mitad del valor que la prestación ejecutada o prometida por la parte damnificada tenía en el momento del contrato".

"La lesión debe perdurar hasta el momento en que se proponga la demanda".

"No podrán ser rescindidos por causa de lesión los contratos aleatorios".

"Quedan a salvo las disposiciones relativas a la rescisión de la división".

La parte recibe una prestación que es inferior al 50 por ciento de la que ha realizado o prometido realizar.

La lesión se da con frecuencia en los contratos de enajenación; empero, es de carácter general. Quedan excluidos los contratos aleatorios; la transacción (art. 1970); la venta forzosa (en subasta) (art. 2922); los contratos con prestación de una sola de las partes; y los contratos gratuitos. Veamos los preceptos correspondientes de la ley italiana:

s. 4 del art. 1448:

"No podrán ser rescindidos por causa de lesión los contratos aleatorios".

Art. 1970:

"La transacción no puede ser impugnada por causa de lesión".

Art. 2922:

"En la venta forzada no tiene lugar la garantía por los vicios de la cosa".

"La misma no puede ser impugnada por causa de lesión". 
En el cód. de Italia existe otro modo de resolver el contrato, que sería el de la intimación a cumplir dirigida contra el contratante que no realiza la prestación que debe. Su art. 1454 expresa:

"A la parte incumplidora la otra podrá intimarle por escrito que cumpla dentro de un término conveniente, bajo apercibimiento de que, transcurrido inútilmente dicho término, el contrato se entenderá, sin más resuelto"

"El término no podrá ser inferior a 15 días, salvo pacto en contrario de las partes o que, por la naturaleza del contrato o de acuerdo con los usos, resulte conveniente un término menor".

"Transcurrido el término sin que se haya cumplido el contrato, éste quedará resuelto de derecho".

$Y$ en cuanto a la importancia del incumplimiento, el art. 1455 del cód. civ. italiano dice:

“No se podrá resolver el contrato si el incumplimiento de una de las partes tuviese escasa importancia, habida cuenta del interés de la otra".

En nuestro cód. civ. nada se establece con respecto a la resolución. Se ignora si demandada lo que nosotros Ilamamos impropiamente "rescisión" de una venta, por no haberse pagado el precio o entregado la cosa, puede el contratante demandado cumplir con el pago o la entrega. Conforme a la ley italiana, ello no puede hacerse. Empero, la solución del derecho germano nos parece más conveniente, cuando se le concede al deudor un plazo suplementario que ha de establecer el acreedor si éste no quiere desistir del contrato. Esta concesión de plazo para la ejecución no es optativa, como en el derecho italiano, sino obligatoria.

El acreedor puede eludir este aplazamiento si prueba que la ejecución del contrato carece de interés para él. Invocará el párrafo II del s. 326. En una vieja traducción de A. García Moreno del BGB, el $2^{\circ}$ apartado del s. 326 a la letra dice:

"Si por consecuencia de la demora tuviese ya interés para la otra parte la ejecución del contrato, tendrá ésta los derechos determinados en el párrafo anterior, sin necesidad de fijar plazo alguno".

Fácilmente se advierte que se ha suprimido la palabra "no" después de "demora".

Nuestro cód. civ. peruano contiene esta doctrina en el art. 1257, que establece:

"Cuando por efecto de la morosidad del deudor, la obligación resultare sin utilidad para el acreedor, podrá és- te rehusar su ejecución y exigir el pago de daños y perjuicios".

Sin embargo, como en derecho civil nuestro la mora no es automática, habría previamente que constituir en mora al deudor.

No acontece, asimismo, como en el derecho germano, que basta la presentación de la demanda (no la citación con ella) para que al deudor se le tenga como moroso. La litis pendentia se equipara a la mora; y la litis pendentia ha de entenderse la iniciación del juicio. La presentación de la demanda importa para el deudor el requerimiento (24). Además, los ss. 291 y 292 del cód. civ. germano le dan a la incoación de la instancia los efectos de la mora. Nótese que la incoación de la instancia no es la simple presentación de la demanda. Se necesita, por lo menos, la notificación de ella, ya que con dicha notificación se producen ciertos efectos jurídicos. Así, existe en el demandado la obligación de explicarse, porque de lo contrario se le seguirá el juicio en su rebeldía.

Nosotros nada de esto tenemos. Nuestra jurisprudencia ha negado, en varias sentencias que la litis pendentia produce los efectos del requerimiento, si el deudor deja llegar el momento de que lo citen con la demanda.

Para la resolución del contrato se requiere que éste se encuentre ya perfeccionado.

Además, ha sobrevenido un hecho o existe una conducta de una de las partes que es posterior a la formación del contrato y que altere las relaciones originarias entre dichas partes, o perturbe su desarrollo.

La resolución concluye ex nunc con el contrato.

El contrato puede resolverse (resiliarse o rescindirse) en virtud del mutuo disenso (contrarius consensus), porque así conviene a las partes que lo celebraron.

Pero también puede ser objeto de resolución el contrato si existe incumplimiento voluntario o involuntario de una de las partes.

En otros derechos, como el italiano, el contrato también se rescindirá si existe dificultad de cumplimiento por excesiva onerosidad de las prestaciones que de él emergen para una de las partes (véase art. 1468 del cód. civ. de Italia). Procede la resolución en este caso,

24 Cons. J. W. HEDEMANN, Trat. de D. Civ., D. de Obligaciones, vol. III, Madrid, 1958, s. 21, No VI, p. 183. Este autor expresa que la mora se da con la presentación de la demanda. Ello es un error. 
porque se ha roto el equilibrio o relación de proporción entre las prestaciones.

La parte lesionada puede pedir la resolución del contrato, o, en otro caso, solicitar que el juez ordene, por sentencia pasada en autoridad de cosa juzgada, el cumplimiento, si es que ello fuere posible. Complementariamente, reclamará indemnización de daños y perjuicios, de la que se libra la parte incumpliente si no incurrió en culpa.

La resolución (o la rescisión conforme al derecho peruano) puede pedirse en el derecho de Italia, sea por incumplimiento voluntario de una parte; sea por incumplimiento involuntario. En este último caso se presenta con posterioridad a la perfección del contrato que la prestación de la parte se hace imposible no por culpa de ésta, sino por caso fortuito o fuerza mayor. Asimismo, la resolución procede en derecho itálico por dificultad en el cumplimiento, debido a la excesiva onerosidad sobrevenida a la obligación que una de las partes debe cumplir.

La resolución se puede pedir aun en el supuesto de que la cosa que conforme al contrato se debe entregar sea indeterminada (genérica, o sea señalada sólo en su especie y cantidad). Empero, la parte demandante puede solicitar no la resolución, sino el cumplimiento del contrato (o sea la entrega de la cosa genérica); y la sentencia ejecutoriada que se pronunciara ordenando la entrega es título ejecutivo dentro del trámite de ejecución de sentencias.

La resolución la pronunciará el juez a pedido (mediante demanda) de la otra parte. Se trata de sentencia firme pronunciada en juicio (que entre nosotros es ordinario, salvo para el contrato de locación-conducción, por las causales enumeradas en los arts. 1529 y 1531 del cód. civ., en cuyo caso procede el juicio sumario de desahucio).

Pedida la resolución, la parte no puede ya cumplir con el contrato: cód. civ. de Italia, art. 1453, s. $3^{\circ}$ : "Desde la fecha de la demanda de resolución, el incumplidor ya no podrá cumplir su obligación".

Admiten los doctrinadores que no puede pedir la resolución del contrato quien tampoco ha cumplido dicho contrato (25).

La resolución opera retroactivamente y en los contratos de tracto sucesivo no obstante la resolución, que-

25 MESSINEO F., Manual de D. Civ. y Com., t. IV, B. Aires, $1955, s .137$, № 10, p. 523. dan firmes las obligaciones ya cumplidas. Dice el art. 1458 del cód. civ. italiano:

“La resolución del contrato por incumplimiento tiene efecto retroactivo entre las partes, salvo el caso de contratos de ejecución continuada o periódica (arriendo), respecto de los cuales el efecto de la resolución no se extiende a las prestaciones ya efectuadas".

"La resolución, aunque se hubiese pactado expresamente, no perjudica los derechos adquiridos por los terceros, salvo los efectos de la transcripción de la demanda de resolución" (26).

Quien no cumple el contrato deberá resarcir el daño sufrido por el otro contratante (daño negativo o positivo), sea que se hubiere conseguido el cumplimiento forzado (a virtud de mandato judicial) del contrato, sea que se hubiere alcanzado la resolución. Ello está previsto en el art. 1453 del cód. civ. de Italia, que declara:

"En los contratos con prestaciones recíprocas, cuando uno de los contratantes no cumpliese su obligación, el otro podrá, a su elección, pedir el cumplimiento o la resolución del contrato, sin perjuicio en todo caso del resarcimiento del daño". (No parece ser que el resarcimiento procede en todo caso, sino cuando el incumplimiento de la parte que ha servido de fundamento para que el juez declare la resolución, se debe a culpa (dolus o negligentia) de quien no cumplió la prestación que le correspondía; pero no si el incumplimiento obedece al casus).

$26 \mathrm{La}$ retroactividad de la resolución en la venta de inmuebles con inscripción del contrato de enajenación en el registro, debe surtir efecto no sólo con la transcripción (entre nosotros, anotación preventiva de la demanda) de la acción de resolución, si se adquiere el inmueble con posterioridad a la transcripción, sino también en el supuesto de que del asiento en que consta la venta aparezca que el comprador quedó debiendo el precio en todo o en parte. Si judicialmente se declara la resolución por la falta de pago del precio, es evidente que esa resolución debe surtir efecto también contra el sub-adquirente que conocía, o debía conocer la existencia de la deuda de precio que estaba expresada en el asiento de inscripción que otorgó el derecho de propiedad a su vendedor. La misma solución debe darse aún en la venta inmobiliaria extra-registro si el sub-adquirente no cuidó de comprobar que las anteriores enajenaciones los precios de cada una de ellas habían sido abonados totalmente, salvo que la deuda estuviera cubierta por la prescripción : 15 años con arreglo al art. 1168 , inc. $2^{\circ}$ del cód. civ. peruano. 
“La resolución podrá ser demandada también aunque el juicio hubiere sido promovido para obtener el cumplimiento; pero no podrá pedirse ya el cumplimiento cuando se hubiera demandado la resolución".

"Desde la fecha de la demanda de resolución, el incumplidor ya no podrá cumplir su obligación".

Aunque una de las partes hubiere incumplido el contrato, no podrá ser resuelto éste si el incumplimiento es de escasa importancia en relación con el interés de la otra parte: art. 1455 cód. civ. de Italia). Por ejemplo, en el art. 1525 del cód. civ. italiano, en aplicación de la regla anterior, se dispone que en el contrato de venta con pacto de reserva de dominio, pese a que se hubiere pactado lo contrario, no se resolverá el contrato si la falta de pago de una sola cuota no supera la octava parte del precio y el comprador conserva el be. neficio del término con relación a las cuotas sucesivas. En nuestro cód. peruano existe un precepto semejante, contenido en el art. 1425, por el que se niega al vendedor el derecho de pedir la resolución de la venta, sino sólo a cobrar el saldo de precio que se le adeuda, si se le ha pagado más de la mitad; pero admite la validez del pacto en contrario.

También en el derecho italiano existe el pacto comisorio expreso o cláusula resolutoria expresa (que entre nosotros puede pactarse, aunque no se encuentre legislada). Se trata de una cláusula del contrato inserta por las partes, que establece que el contrato se resuelve de pleno derecho, en el caso de que determinada obligación no se cumpliera "según las modalidades establecidas"; y que la resolución se opera de derecho cuando la parte interesada declare a la otra que quiere valerse de la cláusula resolutoria.

En realidad, puede pactarse que el contrato se resolverá ipso iure en caso que cualesquiera de las partes incumpla, en todo o en parte, las obligaciones que a cada una le respectan; no sólo una determinada obligación; y no sólo también si se cumple la obligación de manera diversa del modo establecido.

El art. 1456 del cód. civ. italiano es el que legisla sobre este pacto comisorio expreso; no distingue si el defectuoso cumplimiento de la obligación es sin culpa del contratante, o por dolo o negligencia de éste. Sin embargo, MESSINEO (27) hace notar que el cumplimiento de la obligación de modo diverso de las modalidades establecidas por las partes, obedezca a culpa o dolo.

27 Manual de D. Civ. y Com., t. IV, B. Aires, 1955, s. 137, No 11, D), p. 524.
Lo importante es que la resolución funciona si la parte declara judicial o extrajudicialmente, que hace valer la cláusula resolutoria expresa. La demandada puede sin embargo, probar en juicio que cumplió con la prestación en la forma pactada. Además, si la declaración unilateral no se formula, se entenderá que se ha renunciado a valerse del derecho de resolución, por lo que el contrato subsiste en su integridad.

Se prevé por el art. 1457 del cód. civ. italiano que en el contrato se hubiere fijado un término que deba considerarse esencial en interés de una de las partes, para el cumplimiento de la obligación de la otra parte. Dice el dispositivo que si no se ha pactado lo contrario o si existiere uso en contrario, no obstante haber vencido dicho término, puede el contratante acreedor exigir el cumplimiento de la obligación, siempre que dé noticia de ello a la parte deudora dentro de tres días. Agrega el dispositivo que si ello no ocurre, el contrato se entenderá resuelto de derecho aunque no se hubiese pactado expresamente la resolución.

Adviértase que el acreedor pide el cumplimiento tardío de la obligación dentro de tres días contados a partir del vencimiento, por lo que al acreedor le corresponde probar que exigió el pago dentro de dichos tres días. MESSINEO (28) hace notar que este plazo de tres días no se ha establecido en beneficio del deudor en mora, por lo que éste no es admitido a purgar la mora, o sea a cumplir tardíamente. Este es sólo un derecho reservado al acreedor.

Con respecto al término esencial, el cód. del Perú contiene el art. 1254 , inc. $2^{\circ}$, en que no se necesita interpelación o requerimiento para constituir en mora al deudor, "cuando de su naturaleza y circunstancias resultare que la designación de la época en que había de entregarse la cosa, o hacerse el servicio, fue motivo determinante para establecer la obligación".

Otro modo de resolución del contrato con prestaciones recíprocas es por el incumplimiento de una de las partes, pero no se pide por el acreedor la resolución, sino que se requiere al deudor por escrito, para que cumpla con su obligación dentro de cierto término, apercibiéndolo que sino lo cumple el contrato se entenderá resuelto de pleno derecho, o sea extrajudicialmente. Ese término no puede ser inferior a 15 dias. El acreedor no quiere pedirle al juez la resolución, sino que considera que conviene darle al deudor una oportunidad de

28 Manual de D. Civ. y Com., t. IV, B. Aires, 1955, s. 137, No 11, E), p. 525 
cumplir. Todo lo expresado se encuentra contenido en el art. 1454 del cód. civ. de Italia, que previene:

"A la parte incumplidora, la otra podrá intimarle, por escrito, que cumpla dentro de un término conveniente, bajo apercibimiento de que, transcurrido inútilmente dicho término, el contrato se entenderá, sin más, resuelto".

"El término no podrá ser inferior a 15 días, salvo pacto en contrario de las partes o que, por la naturaleza del contrato o de acuerdo con los usos, resulte conveniente un término menor".

"Transcurrido el término sin que se haya cumplido el contrato, éste quedará resuelto de derecho".

Como se observa, también puede estipularse dentro del contrato que éste no quedará resuelto de derecho por el incumplimiento de cierta obligación, sino que el acreedor de ella tendrá derecho a darle un término de gracia al deudor no mayor de cinco o menos días, a fin de que cumpla la prestación. No habrá más que la rescisión o resolución automática, si el término contractualmente señalado y dado, hubiere vencido sin que el deudor hubiere pagado la obligación.

Casos especiales de resolución del contrato en el cód. italiano son:

1) El del arrendador que puede pedir la resolución, si el arrendatario no destina al servicio de la cosa los medios necesarios de ella, o si cambia de manera estable el destino económico de la cosa. Es lo mismo que cuando el cód. peruano en el art. 1529, incs. $1^{\circ}$ y $3 \%$, autoriza la rescisión del contrato si el arrendatario no introduce capitales bastantes, o si da un destino diferente a la cosa. (Véase art. 1618, cód. Italia).

2) Niega la resolución de la transacción por incumplimiento, si la relación preexistente se extinguió por novación, a no ser que se hubiere convenido el derecho de resolución. (Véase art. 1976 cód. civ. Italia).

3) En el mutuo, el art. 1820 del cód. civ. italiano, si el mutuario no cumple la obligación de pagar los intereses convenidos, el mutuante puede pedir la resolución del contrato. Nosotros no tenemos un dispositivo como éste. Sin embargo, siempre se pacta que si deben los intereses correspondientes a determinados plazos, procede que el mutuante cobre el principal del préstamo. Si ello no se estipula, el contrato debe durar el término contractualmente estipulado.
Otra causal de resolución del contrato con prestaciones recíprocas está cuando ocurra la imposibilidad de la prestación por causa no imputable al contratante-deudor. La obligación que era posible, tórnase imposible por casus; ello libera a dicho contratante-deudor.

Empero, la parte que por ese hecho se ha liberado de cumplir su prestación, no tiene derecho a la contra-prestación y debe restituirla si ya la ha recibido, conforme a las reglas de la repetición de lo indebido. La resolución se opera por falta de causa de la obligación, ya que en estos contratos con prestaciones recíprocas, la obligación de una parte tiene por causa la obligación de la otra parte. Lo que se deja relacionado se encuentra en el art. 1463 del cód. civ. italiano, que declara:

“En los contratos con prestaciones recíprocas, la parte liberada por la imposibilidad sobreviniente de la prestación debida no podrá pedir la contra-prestación y deberá restituir la que ya hubiese recibido, de acuerdo con las normas relativas a la repetición de lo indebido"

Sólo en los contratos que transfieren el dominio de una cosa determinada o que constituyen o transfieren derechos reales, la pérdida de la cosa por causa no imputable al enajenante no exime al adquiriente de pagar su obligación, aun cuando la cosa enajenada no le hubiere sido entregada a dicho adquiriente. Lo dice el art. 1465 del cód. civ. italiano. La misma solución tenemos nosotros, pero con respecto a la venta cosas inmuebles, por efecto del art. 1172 de nuestro cód. civ., ya que aunque no le hubiere sido entregado al comprador, éste es ya dueño de él y le corresponderá su desmejora o su pérdida, estando obligado a pagar su precio, no obstante que nada ha recibido, siempre que la desmejora o pérdida no se deba a causa imputable al vendedor.

Otro supuesto legal de resolución del contrato con prestaciones recíprocas, pero en que las prestaciones son de ejecución continuada, o de ejecución periódica, o también de ejecución diferida, es el de la dificultad de la prestación pactada, a consecuencia de un radical cambio de situación, por lo que dicha prestación se hubiere hecho excesivamente onerosa o gravosa en relación a lo que costaba dicha prestación cuando el contrato fue concluido o perfeccionado. Esta resolución es por aplicación de la cláusula "rebus sic stantibus".

Ya lo había en el derecho alemán (véase BGB s. 242) (29). Ahora, el art. 1467 del cód. civ. italiano dispone:

29 Los germanos no tienen en su BGB una norma específica como la del 1467 del cód. civ. italiano, pero sus jueces extraen la doctrina de la imposibilidad jurí- 
"En los contratos de ejecución continuada o periódica o de ejecución diferida, si la prestación de una de las partes hubiera llegado a ser excesivamente onerosa por acontecimientos extraordinarios e imprevisibles, la parte que deba tal prestación podrá demandar la resolución del contrato, con los efectos establecidos en el art. 1458".

dica del s. 242 del BGB, que dice: " El deudor está obligado a efectuar la prestación según lo exigen la buena fe y la intención común de las partes, determinada por los usos y costumbres". Nótese la semejanza con el art. 1328 del cód. civ. peruano, que se mantiene realmente inane para nuestra jurisprudencia. No existe imposibilidad física, porque la obligación se puede cumplir de cualquier modo y a cual-
“La resolución no podrá ser demandada si la onero. sidad sobrevenida entrara en el álea normal del contrato".

"La parte contra quien se hubiere demandado la resolución podrá evitarla ofreciendo modificar equitativamente las condiciones del contrato".

quier costo, pero no se le puede exigir al deudor un esfuerzo que lo extermine económicamente. V. HEDEMANN, D. de Obligaciones, vol. III, s. 20 , No I, p. 167 ss.; LARENZ Karl, Derecho de Obligaciones, t. I, s. 20 , p. 310 ss. En verdad, no se puede exigir al deudor un esfuerzo superior al correspondiente a la obligación. El acreedor que exija una prestación en la que no existe equivalencia con Ia que ha recibido, vulnera la buena fe. 